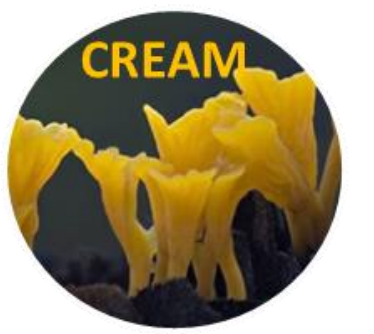

Current Research in Environmental \& Applied Mycology 6 (2): 132-142(2016) ISSN 2229-2225

www.creamjournal.org

Article

CREAM

Copyright (C) 2016

Doi 10.5943/cream/6/2/7

Online Edition

\title{
Endophytic fungal diversity from Cinchona calisaya based on phylogenetic analysis of the ITS ribosomal DNA sequence data
}

Hidayat $\mathbf{I}^{1^{*}}$, Radiastuti $\mathrm{N}^{2}$, Rahayu $\mathrm{G}^{3}$, Achmadi $\mathrm{SS}^{4}$ and Okane $\mathrm{I}^{5}$

\author{
${ }^{1}$ Microbiology Division, Research Center for Biology, Indonesian Institute of Sciences (LIPI), Indonesia, Phone: +62-21- \\ 8765067, Fax: +62-21-8765062 \\ ${ }^{2}$ Biology Department, Faculty of Science and Technology, UIN Syarif Hidayatullah, Indonesia \\ ${ }^{3}$ Biology Department, Faculty of Mathematics and Natural Sciences, Bogor Agricultural University (IPB), Indonesia \\ ${ }^{4}$ Chemistry Department, Faculty of Mathematics and Natural Sciences, Bogor Agricultural University (IPB), Indonesia \\ ${ }^{5}$ Faculty of Life and Environmental Sciences, University of Tsukuba, Japan
}

Hidayat I, Radiastuti N, Rahayu G, Achmadi SS, Okane I 2016 - Endophytic fungal diversity from Cinchona calisaya based on phylogenetic analysis of the ITS ribosomal DNA sequence data. Current Research in Environmental \& Applied Mycology 6(1), 132-142, Doi 10.5943/cream/6/2/7

\begin{abstract}
Cinchona calisaya (quina) is a medicinal plant native to southern Andes forest of South America. This plant and a some of its fungal endophytes have been known for their alkaloid activity against malarial diseases. However, information regarding fungal endophyte diversity within this plant is scarce. Therefore, it is necessary to carry out an endophyte diversity study on $C$. calisaya in order to reveal the entire fungal endophyte assemblage within this plant. The endophytes were analyzed using a culture-dependent method, followed by molecular phylogenetic analysis based on complete nucleotide sequence data generated from the internal transcribed spacer (ITS) of ribosomal DNA region. Several common fungal endophytes genera were determined as follows: Diaporthe/Phomopsis, Glomerella/Colletotrichum, Guignardia/Phyllosticta, Fusarium, Pestalotiopsis, Cladosporium, Aspergillus, Penicillium and Trichoderma. Several members of plant pathogenic and saprobic fungi such as Cercospora, Ilyonectria, Pyrigemmula, Neofusicoccum, Leptosphaerulina and Peyronellaea were also reported here as endophytes. Among the endophytes, species of Diaporthe (Diaporthaceae) were the most common fungal endophytes in the quina plant, followed by species of Colletotrichum (Glomerellaceae) and Fusarium (Nectriaceae). Molecular phylogenetic analysis of ITS sequence data revealed many distinct undetermined clades in the fungal endophyte assemblages, which indicates that many cryptic species are probably present within tissues of $C$. calisaya.
\end{abstract}

Key words - diversity - endophyte - fungi - phylogenetic - quina

\section{Introduction}

Endophytes have been defined as "all organisms inhibiting plant organs that at some time in their life can colonize internal plant tissues without causing apparent harm to the host" (Petrini 1991). Study on endophytic fungi, in particular on medicinal plants, has become more important in recent years, due to their potential as source of various metabolites for agrochemical and medicinal purposes (Strobel \& Daisy 2003). In diversity and systematic studies, numerous endophytic isolates have been published as novel taxa, due to their unique phenotype and genotype characteristics (Hyde \& Soytong 2008). Studies on endophytic fungiand their metabolites properties have increased through application of molecular methods, however, the majority of endophytic fungal species probably remain unidentified. 
Cinchona calisaya Wedd. (common name: quina) is a medicinal plant belonging to plant family Rubiaceae, native to southern Andes forest of South America (Andersson \& Antonelli 2005). Quina was introduced to Indonesia from Bolivia in 1852, and was first planted in Cibodas area (West Java). Currently, Gambung area (West Java) is the largest quina plantation in Indonesia. Quina plant has been known for its alkaloidal properties such as quinine, quinidine, cinchonidine and cinchonine (Song 2009). Quinine is the most famous Cinchona alkaloids due to its activity against the causal agent of malarial diseases at erythrocyte stage, parasite Plasmodium sp. Several endophytic fungi from the quina plant, such as members of Diaporthe (asexual morph: Phomopsis) and Arthrinium were also capable of producing Cinchona alkaloids on artificial medium (Shibuya et al. 2003).

Study on fungal diversity from Cinchona spp. in Indonesia is not new (Simanjuntak et al. 2002, Shibuya et al. 2003, Mumpuni et al. 2004, Winarno 2006, Maehara et al. 2010). However, most studies focused on exploring metabolites produced by the endophytic fungi isolated from bark of the quina, and therefore, little information can be evaluated for estimating the diversity of endophytic fungi from Cinchona spp. The majority of fungal endophytes of quina from previous studies in Indonesia were unidentified (Maehara et al. 2010). However, several fungal genera such as Arthrinium, Diaporthe, Phomopsis, Penicillium and Xylaria were revealed as common endophytes from quina (Simanjuntak et al. 2002, Shibuya et al. 2003, Mumpuni et al. 2004, Winarno 2006, Maehara et al. 2010).

Fungi have traditionally been identified by observing their morphological characteristic, mainly reproductive structures. However, since the majority endophytic fungi are mycelia sterilia, identification of this fungal group is, therefore, more difficult (Lacap et al. 2003). In recent years, several studies have shown that genetic-based methods, such as molecular phylogenetic analysis, can successfully be employed to identify mycelia sterilia fungi (Guo et al. 2001, Sánchez Márquez et al. 2007, Rungjindamai et al. 2008, Jeewon et al. 2013). In this study, diversity of fungal endophytes from C. calisaya was determined by performing molecular analysis based on the internal transcribed spacer (ITS) ribosomal DNA region. Prior to phylogenetic analysis, endophytic fungal isolates were firstly grouped into morphotypes, based on similarity in colony and several microscopic characters.

\section{Materials \& Methods}

\section{Specimen Collection}

Specimen collection was conducted at quina plantation managed by the Research Center for Tea and Quina, Gambung, West Java, Indonesia on 29 September 2012. The specimens were collected from five individual healthy plants by cutting off asymptomatic flowers, leaves, petioles, stems, barks and roots of $C$. calisaya. Five pieces of each organ were placed in zipped plastic bags. The plastic bags were sealed and labelled with the name of the host, collection site, date and collector/s. All materials were kept in ice boxes prior to isolation in the laboratory.

\section{Isolation}

The isolation protocol of endophytic fungi referred to the method described by Mostert et al. (2001) with modification. Samples were washed thoroughly in running water before processing. The samples were further surface-sterilized by immersing in $70 \%$ ethanol $(\mathrm{v} / \mathrm{v})$ for $1 \mathrm{~min}$, followed by soaking in sodium hypochlorite $(\mathrm{NaOCl})(\mathrm{v} / \mathrm{v}) 3 \%$ for $3 \mathrm{mins}$, and rinsed once $70 \%$ ethanol $(20$ seconds). After sterilization, the samples were rinsed three times in sterile distilled water, and dried with sterile paper for at least 6 hours. The sterile distilled water of the final rinse was poured onto the agar medium as a isolation quality control of sterilization process. After drying, samples were cut into segments approximately $1 \times 2 \mathrm{~cm}$ and placed on the surface of Malt Extract Agar (MEA) (Difco, USA) (4 segments/petri dishes). All petri dishes were incubated at room temperature. Three replicates were made for each sample. The growth of endophytic fungi mycelium were observed every day, for about 30 days. The growing colonies were purified using a hyphal tip isolation method to obtain a pure culture. All pure isolates were grouped into morphotypes based on culture characteristics on Potato Dextrose Agar (PDA) medium and microscopic structures. All isolated used in this study are deposited at Bogor Agricultural University Culture Collection (IPBCC), Indonesia (Fig. 1). 


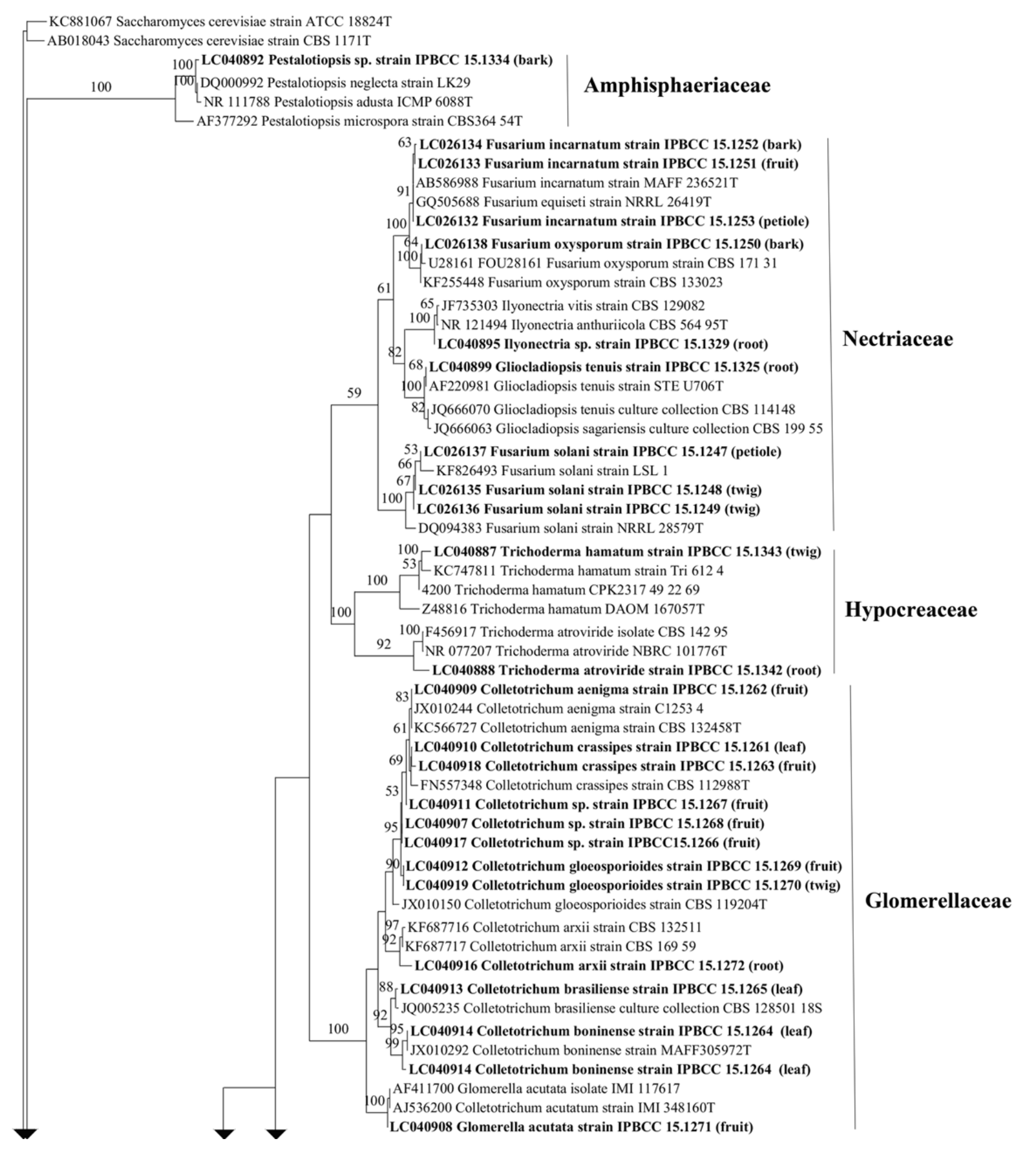

Fig. 1 - Maximum Parsimony (MP) tree showing phylogenetic relationship between 96 sequences of endophytic fungi from $C$. calisaya (bold) with related species based on the ITS rDNA sequences. Bootstrap value $>50 \%$ are shown at the branch nodes.

\section{DNA Extraction, PCR Amplification and Sequencing}

The endophytic fungal isolates were cultured in $5 \mathrm{~mL}$ of Potato Dextrose Broth (PDB) (Difco, USA) for 7-days. DNA was isolated by using Phytopure ${ }^{\mathrm{TM}}$ DNA extraction kit (GE Healthcare, UK) following the manufacturer's protocol. DNA amplification was conducted using Polymerase Chain Reaction (PCR) method. The $25 \mu \mathrm{L}$ PCR mixture contained: $10 \mu \mathrm{L}$ nuclease free water, $12.5 \mu \mathrm{L}$ DreamTaq $^{\circledR}$ green master mix (Thermo scientific, USA), $0.5 \mu \mathrm{L}$ of forward and reverse primer, $0.5 \mu \mathrm{L}$ DMSO, and $1 \mu \mathrm{L}$ DNA template. The primer pairs of ITS5 (forward) (5'TCCTCCGCTTATTGATATGC-3') and ITS4 (reverse) (5'-TCCGTAGGTGAACCTGCGC-3') (White et al. 1990) were used to amplify the ITS region including 5.8S rDNA. The PCR condition for 
Fig. 1 - (Cont.)

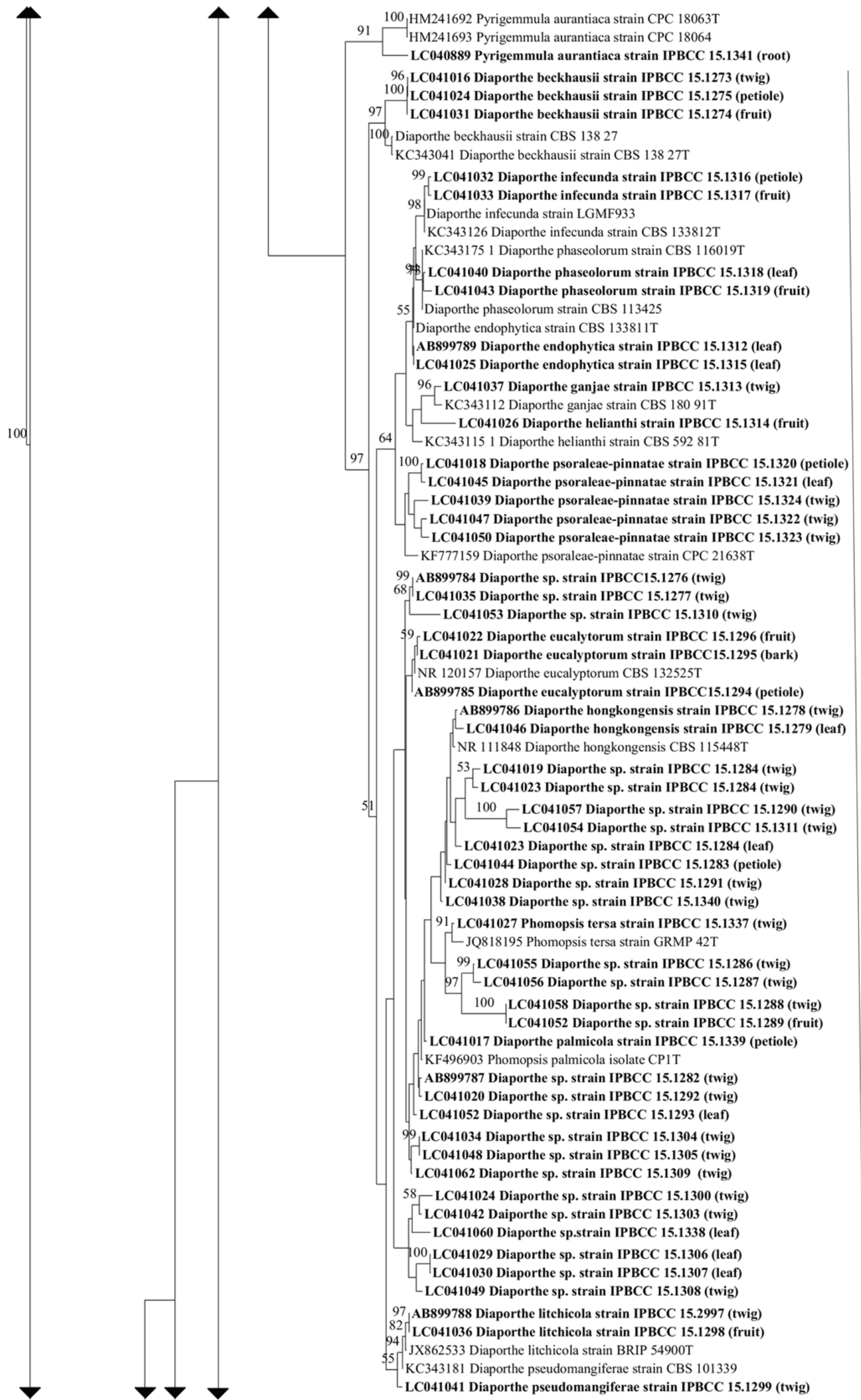

Diaporthaceae

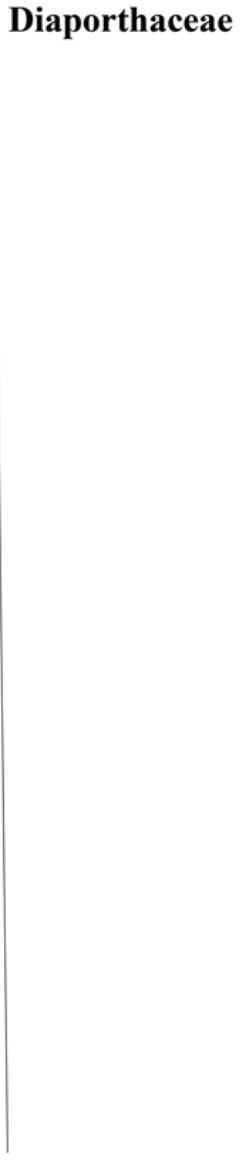


Fig. 1 - (Cont.)

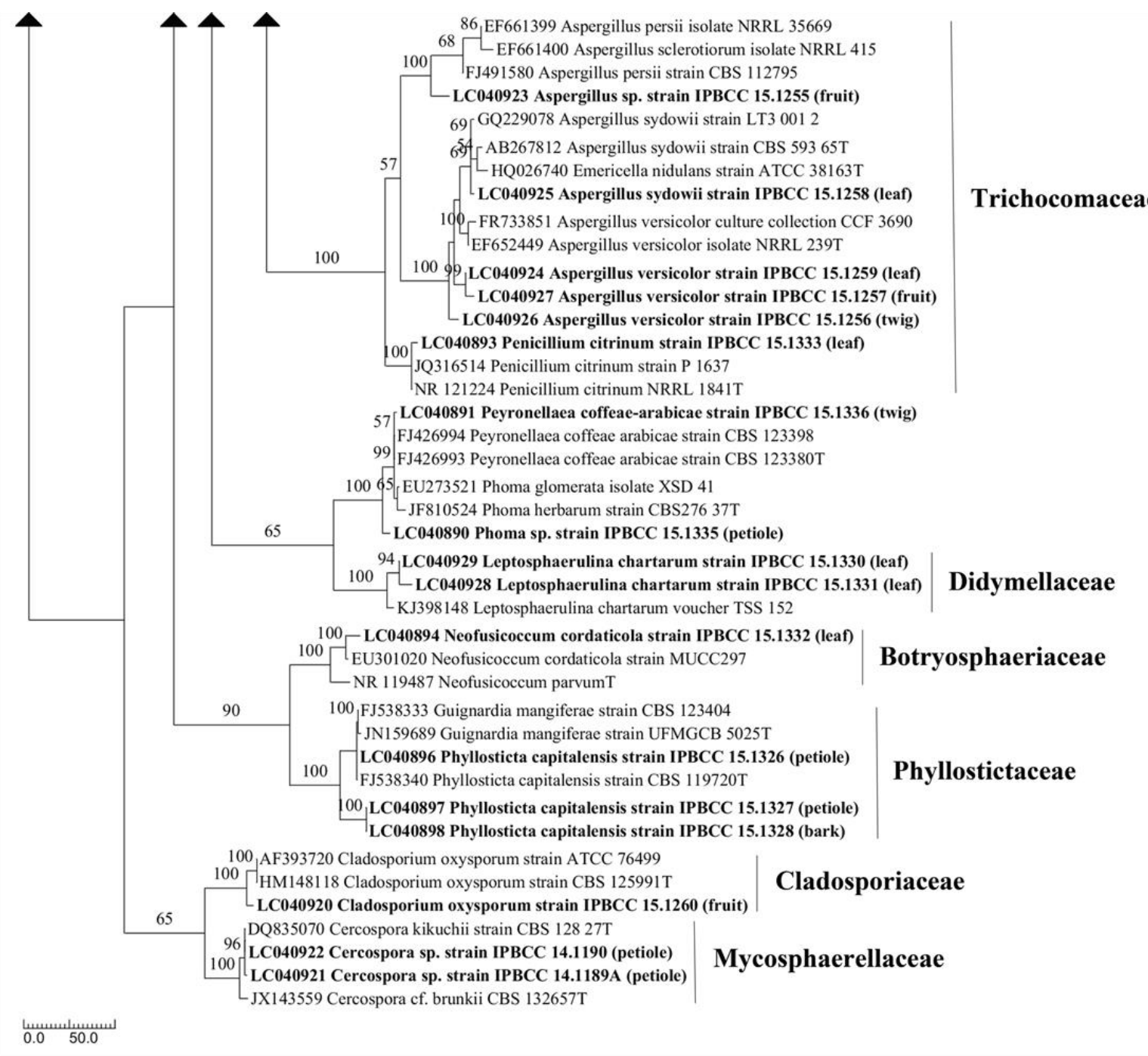

ITS region was set as follow: $90 \mathrm{~s}$ at $95{ }^{\circ} \mathrm{C}$ for initial denaturation, followed by 35 cycles of $30 \mathrm{~s}$ at 95 ${ }^{\circ} \mathrm{C}$ denaturation, $30 \mathrm{~s}$ at $55^{\circ} \mathrm{C}$ annealing, $90 \mathrm{~s}$ at $72{ }^{\circ} \mathrm{C}$ extension and $5 \mathrm{~min}$ at $72{ }^{\circ} \mathrm{C}$ for the final extension. All PCR reactions were conducted using T100 thermal cycler (Bio-Rad, USA). The detection of amplification products was performed by electrophoresis at $100 \mathrm{~V}$ for $30 \mathrm{~min}$ in an $1 \%$ $(\mathrm{w} / \mathrm{v})$ agarose gel soaked in $1 \times$ TAE buffer. $1 \mathrm{~kb}$ DNA ladder was used as a marker during the electrophoresis. The gel was soaked in ethidium bromide (EtBr) for $30 \mathrm{~min}$ and visualized under a Gel Documentation system (Gel Doc Bio-Rad, USA). Purified PCR products were sent to $1^{\text {st }}$ BASE (Malaysia) for sequencing.

\section{Molecular Phylogenetic Analysis}

New nucleotide sequences obtained from the respective primer pairs (ITS5-F and ITS4-R) were examined and refined by direct examination using Chromas Pro 1.41 software (Technelysium Pty Ltd., Australia). New sequences determined in this study were deposited in GenBank (NCBI and DDBJ). The GenBank accession number of all sequences was showed in figure 1. Newly ITS sequences of endophytic fungi from $C$. calisaya were aligned using MUSCLE (multiple sequence alligment with high accurancy and high throughput) implemented in MEGA (molecular evolutionary genetics analysis) version 6 (Tamura et al. 2013). Saccharomyces cerevisiae strain ATCC 18824 (KC881067) and Saccharomyces cerevisiae strain CBS 1171 (AB018043) were used as outgroup in analyses. Phylogenetic analysis was conducted using the Maximum Parsimony (MP) method in PAUP* 4.0b10 (Swofford 2002). All characters were equally weighted and unordered. Aligment gaps were 
treated as missing data. MP analysis was conducted using a heuristic search with tree bisection and reconnection (TBR) branch swapping with 1000 random addition sequence replicates. The stepwise addition option set as random and maximum tree number was set at 500. Tree length (TL), consistency index $(\mathrm{CI})$, retention index (RI), related consistency index (RC) and homoplasy index (HI) were also calculated. Statistical support for the internal branches was estimated by bootstrap (BS) analysis based on 1000 replication (Felsenstein 1985). BS values of $50 \%$ or higher than that are shown. The phylogenetic tree was refined using TreeGraph 2 (Stöver \& Müller 2010).

\section{Results}

\section{Morphotype}

A total 687 isolates were obtained from different organs of quina. These isolates were grouped into 96 morphotypes based on the characteristic of cultures on PDA medium and microscopic structures observation (data not shown). Several sporulating fungal endophytes were determined belonging to Trichoderma (2 morphotypes), Fusarium ( 7 morphotypes), Colletotrichum (12 morphotypes), Pestalotiopsis (1 morphotype), Penicillium (1 morphotype), Aspergillus (5 morphotypes), Phyllosticta (3 morphotypes), Cladosporium (1 morphotype) and Phomopsis (53 morphotypes). The remaining 11 morphotypes were unsporulated after $30 \mathrm{~d}$ incubation on PDA. Representatives of each morphotype were further selected for molecular phylogenetic analysis.

\section{Phylogenetic analyses}

The alignment data matrix consisted of 167 sequences (including outgroup) and 822 total characters, of which 42 characters $(5.1 \%)$ were variable, 195 characters $(23.7 \%)$ were constant, and 585 characters $(71.2 \%)$ were informative for parsimony analysis. The most parsimonious tree was generated in 4067 steps $(\mathrm{CI}=0.301, \mathrm{RI}=0.790, \mathrm{RC}=0.238, \mathrm{HI}=0.699)$ (Fig. 1). The ITS sequence analysis of 96 endophytic fungal morphotypes from quina showed that all sequences were divided into 11 distinct fungal families, viz, Amphisphaeriaceae (1 sequence), Nectriaceae (9 sequences), Hypocreaceae (2 sequences), Glomerellaceae (12 sequences), Diaporthaceae (53 sequences), Trichocomataceae (6 sequences), Didymellaceae (2 sequences), Botryosphaeriaceae (1 sequence), Phyllostictaceae (3 sequences), Cladosporiaceae (1 sequence) and Mycosphaerellaceae (2 sequences). However, the familial placement of three morphotype sequences belong to order Pleosporales, viz, Pyrigemmula aurantiaca strain IPBCC 15.1341, Phoma sp. strain IPBCC 15.1335 and Peyronellaea coffeae-arabicae strain IPBCC 15.1336 were unknown.

In the Nectriaceae clade (59\% BS), nine sequences of the endophytic fungi from C. calisaya were divided into three distinct sub-clades. The first sub-clade containing $F$. incarnatum strain IPBCC 15.1251, IPBCC 15.1252, IPBCC 15.1253; and F. oxysporum strain IPBCC 15.1250 with $100 \%$ BS. The second sub-clade containing Ilyonectria sp. strain IPBCC 15.1329 and Gliocladiopsis tenuis strain IPBCC 15.1325 (82\% BS), and the third sub-clade containing F. solani strain IPBCC 15.1247, IPBCC 15.1248 and IPBCC 15.1249 ) with $100 \%$ BS. The family Nectriaceae is sister clade to Hypocreaceae clade (100\%BS) (contains T. hamatum strain IPBCC 15.1343 and T. atroviride strain IPBCC 15.1342), however, with low bootstrap support. Both families belong to order Hypocreales.

In the Glomerellaceae clade (100\% BS), seven species of Glomerella/Colletotrichum were determined, viz, Coll. aenigma strain IPBCC 15.1262, Coll. crassipes strain IPBCC 15.1261 and IPBCC 15.1263, Coll. gloeosporioides strain IPBCC 15.1269 and IPBCC 15.1270, Coll. arxii strain IPBCC 15.1272, Coll. brasiliense strain IPBCC 15.1265, Coll. boninense strain IPBCC 15.1264 (2 sequences), and G. acutata strain IPBCC 15.1271. In this clade, the species name of Colletotrichum spp. strain IPBCC15.1266, IPBCC15.1267 and IPBCC15.1268 were undetermined.

Diaporthaceae clade (97\% BS) is the largest family among members of endophytic fungi from $C$. calisaya with 53 representative sequences (generated from 53 morphotypes). Fourteen species of Diaporthe/Phomopsis were determined, viz, D. beckhausii strain IPBCC 15.1273, IPBCC 15.1274 and IPBCC 15.1275; D. infecunda strain IPBCC 15.1316 and IPBCC 15.1317 ; D. phaseolorum strain IPBCC 15.1318 and IPBCC 15.1319; D. endophytica strain IPBCC 15.1312 and IPBCC 15.1315; D. 
ganjae strain IPBCC 15.1313, D. helianthi strain IPBCC 15.1314, D. psoraleae-pinnatae strain IPBCC 15.1320, IPBCC 15.1321, IPBCC 15.1322, IPBCC 15.1323 and IPBCC 15.1324;, D. eucalyptorum strain IPBCC15.1294, IPBCC15.1295 and IPBCC15.1296; D. hongkongensis strain IPBCC 15.1278 and IPBCC 15.1279; Phomopsis tersa strain IPBCC 15.1337, D. palmicola strain IPBCC 15.1339, D. litchicola strain IPBCC 15.2997 and IPBCC 15.2998; and D. pseudomangiferae strain IPBCC 15.1299.

From a total six fungal endophyte sequences within Trichocomaceae clade (100\% BS), five sequences nested within Aspergillus clade with 57\% BS. They were determined as A. versicolor strain IPBCC 15.1256, IPBCC 15.1257 and IPBCC 15.1259; A. sydowii strain IPBCC 15.1258, and one unknown species (Aspergillus sp. strain IPBCC 15.1255). The remaining sequence was determined as Pen. citrinum strain IPBCC 15.1333 (100\% BS).

The family Didymellaceae of Pleosporales (100\% BS) contains a single species, Leptosphaerulina chartarum strain IPBCC 15.1330 and IPBCC 15.1331. This family is sister clade to the clade containing Pyr. coffeae-arabicae strain IPBCC 15.1336 and Phoma sp. strain IPBCC 15.1337 with 65\% BS. Botryosphaeriaceae clade (order Botryosporales) (100\% BS) also contains a single endophytic fungal species, namely, Neofusicoccum cordaticola strain IPBCC 15.1332. This clade is sister clade to Phyllostictaceae clade of which also contains a single species, namely, Phy. capitalensis strain IPBCC 15.1326, IPBCC 15.1327 and IPBCC 15.1328 with 90\% BS.

Representatives of order Capnodiales $(65 \%$ BS) comprise two families, namely, Mycospharellaceae (100\% BS) and Cladosporiaceae (100\% BS). The Mycosphaerellaceae clade contains two unknown species of Cercospora spp. strain IPBCC 14.1189 and IPBCC 14.1190, while the Cladosporiaceae clade contains a single species, namely, Cladosporium oxysporum strain IPBCC 15.1260.

The ITS tree also showed that many species of endophytic fungi from $C$. calisaya were not organ specific (Fig. 1). These include $F$. incarnatum on bark, fruits and petioles; $F$. solani on bark and petioles; Coll. crassipes on leaves and fruits; Coll. gloeosporioides on fruits and twigs; D. beckhausii on twigs, petioles and fruits; $D$. infecunda on petioles and fruits; D. phaseolorum on leaves and fruits; $D$. psoraleae-pinnatae on petioles, leaves and twigs; $D$. eucalyptorum on fruits and bark; $D$. hongkongensis on twigs and leaves; D. litchicola on twigs and fruits; A. versicolor on leaves, fruits and twigs; and Phy. capitalensis on petioles and bark. However, several species of endophytic fungi from C. calisaya indicated specificity to particular organs, such as Coll. boninense, D. endophytica and $L$. chartarum on leaves, and Cercospora spp. on petioles.

\section{Discussion}

This study provides essential information regarding fungal diversity within a healthy tree of $C$. calisaya from all organs of the plant. In contrast, previous studies on fungal endophytes from Cinchona spp. were restricted only to twigs and bark (Simanjuntak et al. 2002, Shibuya et al. 2003, Mumpuni et al. 2004, Winarno 2006, Maehara et al. 2010). In these studies, several fungal genera, viz, Xylaria, Diaporthe, Schizophyllum, Penicillium, Fomitopsis and Arthrinium were determined as endophytic from $C$. ledgeriana and C. pubescens (Simanjuntak et al. 2002, Maehara et al. 2010). However, there has been no comprehensive information regarding fungal species assemblage and diversity from available publications of endophytic fungi from quina (Cinchona spp.) until now. These circumstances definitely undermine the potential of quina as host of many fungal species, because in fact, a hundred of fungal endophytes potentially colonize a single host plant (Sánchez Márquez et al. 2007).

In this study, we determine 35 species of fungal endophytes belong to 15 genera and 11 families from $C$. calisaya based on combination of conventional and molecular phylogenetic methods. The fungal endophyte taxa include several common endophytes genera such as Colletotrichum (13 morphotypes), Diaporthe (53 morphotypes), Phyllosticta (3 morphotypes), Fusarium (7 morphotypes), Pestalotiopsis (1 morphotype), Cladosporium (1 morphotype), Aspergillus (5 morphotypes), Penicillium (1 morphotype), Trichoderma (2 morphotypes). Several uncommon fungal endophytic genera such as Cercospora (2 morphotypes), Ilyonectria (1 morphotype), Pyrigemmula (1 morphotype), Neofusicoccum (1 morphotype), Leptosphaerulina (2 morphotypes) and Peyronellaea (1 morphotype) were also determined from C. calisaya. Among them, members of Diaporthaceae (14 
known species from 53 morphotypes) were found as common endophytic fungi from C. calisaya followed by Glomerellaceae (6 known species from 13 morphotypes), Nectriaceae (4 known species from 9 morphotypes) and Trichocomaceae (3 known species from 6 morphotypes). Species of Diaporthaceae and Glomerellaceae, are well-known as common endophytes found in various plants (Hyde \& Soytong 2008, Photita et al. 2005).

Current results on the endophytic fungal diversity assemblage and composition from C. calisaya were probably affected by the isolation method used in this study, because fungal endophytes study is generally method-dependent process (Guo et al. 2001). For example, some fungi require selective media (Guo et al. 2001), and some other emerging late on the isolation media and need about 3-12 months monitoring. Therefore, Hyde \& Soytong (2008) noted that scientific papers regarding diversity of fungal endophytes should always mention the effect of method to the fungal endophytes assemblage obtained in the study. We recognize that the current endophytic fungi from $C$. calisaya were dominated by fast growing fungi. It is due to the current data were obtained from the isolates grown up to 30 days incubation. Majority of the slow growing fungi ( $>30$ days incubation) were probably not determined in this study.

It is noticeable that two morphotypes of Cercospora were found in the current study. Members of Cercospora are generally recognized as plant pathogenic fungi, causing leaf spot and necrotic lesions, found in almost all major families of dicotyledonous, most monocotyledonous families, some gymnosperms and ferns in most climatic regions (Pollack 1987). Members of Cercospora were rarely found as endophytes. Only a single species, Cer. kikuchii, has been recorded as an endophyte (Costa-Silva et al. 2010, 2014). This species has also been known as destructive pathogenic fungus on soybean [Glycine max (L.) Merr.], cowpea [Vigna unguiculata (L.) Walp.] and butter bean (Phaseolus lunatus L.) (Costa-Silva et al. 2010), and also potential as lipase producer (Costa-Silva et al. 2010, 2014). Another record of endophytic Cercospora was guanacastane diterpenes producing isolate (Feng et al. 2014), however, the species name of the fungus was unknown. These reports demonstrate the potential of endophytic Cercospora isolates as secondary metabolites and enzymes producer.

Identification of fungi, in particular endophytes, has been proven to be difficult for nonspecialist. Even for mycologists, identification of several common endophytic taxa such as Colletotrichum, Diaporthe, Phyllosticta, Fusarium, Pestalotiopsis, Cladosporium, Aspergillus and Penicillium has still been complicated, in particular, when the mycologists have to combine several genes or regions to identify a single species. Development of DNA barcode in fungi (Begerow et al. 2010) has not proven to be helpful in fungal endophyte identification. Numerous unidentified species found in the current study based on molecular phylogeny identification method using ITS rDNA sequence, a universal DNA barcode for fungi sensu Schoch et al. (2012). For example, only 14 morphotypes were successfully determined until species level from 53 morphotypes of Diaporthe (Fig. 1) using phylogenetic analysis based on ITS rDNA sequence. The remaining sequences belong to species complex or undetermined species. We tried conducting separate phylogenetic analysis by combining ITS dataset with sequence dataset from EF1- $\alpha$ gene, a region that commonly used to provide a better estimate of the species boundaries of Diaporthe (Udayanga et al. 2012a, b; Gomes et al. 2013), but the phylogenetic tree generated from this dataset did not provide better resolution in determining fungal species within the Diaporthe clade (data not shown). Multilocus molecular phylogenetic analysis involving nucleotide sequences generated from other gene regions are currently required for determination of members of Diaporthe to species level (Udayanga et al. 2012a, b; Gao et al. 2005). The same situation was found on the other important fungal endophytic taxa such as species of Colletotrichum and Phyllosticta. Colletotrichum, Diaporthe and Phyllosticta species are common endophytes found on various plants in different geographic areas, and are also important plant pathogens (Gao et al. 2005). The current study showed that more than one species from a single genus were found on the same organ of $C$. calisaya, such as $F$. incarnatum and F. solani on bark; Coll. crassipes and Coll. gloeosporioides on fruits; D. beckhausii, D. infecunda, D. phaseolorum and D. psoraleae-pinnatae on petioles; D. beckhausii, D. psoraleae-pinnatae, D. hongkongensis and D. litchicola on twigs (Fig. 1). Therefore, further comprehensive molecular studies on these fungal groups as endophytes are necessary to apropriately reveal their diversity in nature. 
The many undetermined clades revealed in the current study indicate the richness of fungal endophytes within $C$. calisaya. This data, not included slow growing and unculturable fungal endophytes, showed a high diversity of the fungal endophytes living within different organs of $C$. calisaya. Indeed, this plant possibly hosts many cryptic species of the fungal endophytes. However, further investigation involving multigene molecular phylogenetic analysis is necessary to determine the identity of many unknown morphotypes. Hyde \& Soytong (2008) suggested that most of previous research of fungal endophytes assemblage within various plants may have provided incomplete data. It was possibly due to limitation of the available methods to reveal the entire fungal endophyte assemblage within plants. The current available fungal identification method, that involving multigene phylogenetic analysis, has been proven to be costly and time consuming. This situation leaves large challenges for mycologists to discover better methods to reveal the entire fungal endophytes within plants.

\section{Acknowledgements}

This paper is an extended version of Nani Radiastuti's Ph.D. thesis, which was financially supported by the SATREPS project between NITE-NBRC (Japan) and LIPI (Indonesia). Bogor agricultural university culture collection (IPBCC) is acknowledged for providing space and equipment during several parts of the laboratory works. The Research Center for Tea and Quina, Gambung (West Java province, Indonesia) is also thanked for specimen collection.

\section{References}

Andersson L, Antonelli A. 2005 - Phylogeny of the tribe Cinchoneae (Rubiaceae), its position in Cinchonoideae, and description of a new genus, Ciliosemina. Taxon 54, 17-28.

Begerow D, Nilsson H, Untherseher M, Maier W. 2010 - Current state and perspectives of fungal DNA barcoding and rapid identification procedures. Applied Microbiology and Biotechnology 87, 99-108.

Costa-Silva TA, Said S, Souza CRF, Oliveira WP. 2010 - Stabilization of Endophytic Fungus Cercospora kikuchii Lipase by Spray Drying in the Presence of Maltodextrin and $\beta$-Cyclodextrin. Drying Technology 28, 1245-1254. DOI: 10.1080/07373937.2010.498068.

Costa-Silva TA, Souza CRF, Oliveira WP, Said S. 2014 - Characterization and spray drying of lipase produced by the endophytic fungus Cercospora kikuchii. Brazilian Journal of Chemical Engineering 31, 849-858. http://dx.doi.org/10.1590/0104-6632.20140314s00002880.

Felsenstein J.1985 - Confidence limits on phylogenetic: an approach using the bootstrap. Evolution 3, 783-791.

Feng Y, Ren F, Niu S, Wang L, Li L, Liu X, Che Y. 2014 - Guanacastane diterpenoids from the plant endophytic fungus Cercospora sp. Journal of Natural Products 77, 873-881. doi: $10.1021 / \mathrm{np} 4009688$.

Gao XX, Zhou H, Xu DY, Yu CH, Chen YQ, Qu LH. 2005 - High diversity of endophytic fungi from the pharmaceutical plant, Heterosmilax japonica Kunth revealed by cultivation independent approach. FEMS Microbiol Letters 249, 255-266.

Gomes RR, Glienke C, Videira SIR, Lombard L, Groenewald JZ, Crous PW. 2013 - Diaporthe: a genus of endophytic, saprobic and plant pathogenic fungi. Persoonia 31, 1-41. doi: $10.3767 / 003158513 \times 666844$.

Guo LD, Hyde KD, Liew ECY. 2001 - Detection and identification of endophytic fungi within frond tissues of Livistona chinensis based on rDNA sequence. Molecular Phylogenetics and Evolution $20,1-13$.

Hyde KD, Soytong K. 2008 - The fungal endophyte dilemma. Fungal Diversity 33, 163-173.

Jeewon R, Wang HK, Ittoo J, Liu AR, Mahadeb D, Jaufeerally-Fakin Y. 2013 - DNA based identification and phylogenetic characterisation of endophytic and saprobic fungi from Antidesma madagascariense, a medicinal plant in Mauritius. Journal of Mycology. Article ID 781914: 10 pages, http://dx.doi.org/10.1155/2013/781914 
Lacap DC, Hyde KD, Liew ECY. 2003 - An evaluation of the fungal 'morphotype' concept based on ribosomal DNA sequences. Fungal Diversity 12, 53-66.

Maehara S, Simanjuntak P, Ohashi K, Shibuya H. 2010 - Composition of endophytic fungi living in Cinchona ledgeriana (Rubiaceae). Journal of Natural Medicines 64, 277-230. doi: 10.100/s11418-009-0380-2.

Mostert L, Crous PW, Kang JC, Philips AJL. 2001 - Species of Phomopsis and Libertella sp. occuring on grapevines with specific reference to South Africa: morphological, cultural, molecular and pathological characterization. Mycologia 93, 146-167.

Mumpuni E, Amalia, Parwati T, Simanjuntak P. 2004 - Produksi asam lemak oleat oleh mikroba endofit Sporodiobolus salmonicolor dari tumbuhan kina (Cinchona pubescens Vahl.). Alchemy 3, $16-21$.

Petrini O. 1991 - Fungal endophytes of tree leaves. 179-197, in Andrews JH, Hirano SS. (eds.). Microbial ecology of leaves. New York, Springer-Verlag.

Photita W, Taylor PWJ, Ford R, Lumyong P, McKenzie EHC, Hyde KD, Lumyong S. 2005 Morphological and molecular characterization of Colletotrichum species from herbaceous plants in Thailand. Fungal Diversity 18, 117-133.

Pollack FG. 1987 - An annotated compilation of Cercospora names. Mycological Memoirs 12, 1-212.

Rungjindamai N, Pinruan U, Choeyklin R, Hattori T, Jones EBG. 2008 - Molecular characterization of basidiomycetous endophytes isolated from leaves, rachis and petioles of the oil palm, Elaeis guineensis, in Thailand. Fungal Diversity 33, 139-162.

Sánchez Márquez S, Bills GF, Zabalgogeazcoa I. 2007 - The endophytic mycobiota of the grass Dactylis glomerata. Fungal Diversity 27, 171-195.

Schoch CL, Seifert KA, Huhndorf A, Robert V, Spouge JL, Levesque CA, Chen W. 2012 - Fungal Barcoding Consortium. Nuclear ribosomal internal transcribed spacer (ITS) region as a universal DNA barcode marker for Fungi. Proceedings of the National Academy of Sciences 109, 6241-6246. doi: 10.1073/pnas.1117018109.

Shibuya H, Kitamura C, Maehara S, Nagahata M, Winarno H, Simanjuntak P, Kim HS, Wataya Y, Ohashi K. 2003 - Transformation of Cinchona alkaloids into 1-N-Oxide derivatives by endophytic Xylaria sp. isolated from Cinchona pubescens. Chemical and Pharmaceutical Bulletin 51, 71-74.

Simanjuntak P, Parwati T, Bustanussalam, Prana TK, Wibowo S, Shibuya H.2002 - Isolasi dan kultivasi mikroba endofit penghasil senyawa alkaloid kinkona dari Cinchona spp. Jurnal Mikrobiologi Indonesia 7, 27-30.

Song CE. 2009 - An overview of Cinchona alkaloids in chemistry. 1-10 pp. In: Song CE. (Ed.). Cinchona alkaloids in synthesis and catalysis, ligands, immobilization and organocatalysis, Weinheim, WILEY-VCH Verlag GmbH \& Co. KGaA.

Stöver BC, Müller KF. 2010 - TreeGraph 2: Combining and visualizing evidence from different phylogenetic analyses. BMC Bioinformatics 11, 1-9. doi: 10.1186/1471-2105-11-7.

Strobel G, Daisy B. 2003 - Bioprospecting for microbial endophytes and their natural products. Microbiology and Molecular Biology Reviews 67, 491-502.

Swofford DL.2002 -PAUP*: Phylogenetic analysis using parsimony (*and other methods), version 4. Massachusetts, Sinauer Associates.

Tamura K, Stecher G, Peterson D, Filipski A, Kumar S. 2013 - MEGA6: Molecular Evolutionary Genetics Analysis version 6.0. Molecular Biology and Evolution 30, 2725-2729. doi: 10.1093/molbev/mst197.

Udayanga D, Liu X, Crous PW, McKenzie EHC, Chukeatirote E, Hyde KD. 2012a - A multi-locus phylogenetic evaluation of Diaporthe (Phomopsis). Fungal Diversity 56, 157-171.

Udayanga D, Liu X, Crous PW, McKenzie EHC, Chukeatirote E, Hyde KD. 2012b - Multilocus phylogeny reveals three new species of Diaporthe from Thailand. Cryptogamie Mycologie 33, 295-309.

Winarno EK. 2006 - Produksi alkaloid oleh mikroba endofit yang diisolasi dari batang kina Cinchona ledgeriana Moens dan Cinchona pubescens Vahl (Rubiaceae). Jurnal Kimia Indonesia 1, 59-66. 
White TJ, Bruns T, Lee S, Taylor J. 1990 - Amplification and direct sequencing of fungal ribosomal RNA genes for phylogenetics. 315-322, in Innis MA et al. (eds.). PCR protocols: A guide to molecular methods and applications. San Diego, Academic Press. 